\title{
Changing Human-Environment Interactions in Medium Mountains, the Apuseni Mts (Romania) as a Case Study
}

\section{TELBISZ Tamás ${ }^{1, *}$, IMECS Zoltán $^{2}$, MARI László ${ }^{1}$ and BOTTLIK Zsolt ${ }^{3}$}

\author{
${ }^{1}$ Department of Physical Geography, Eötvös University, Budapest, Hungary, 1117 Budapest, Pázmány Péter sétány 1/C. \\ ${ }^{2}$ Department of Geography in Hungarian, Babeş-Bolyai University, 400006, Cluj-Napoca, Str. Clinicilor 5-7, Romania \\ ${ }^{3}$ Department of Regional Science, Eötvös University, Budapest, Hungary, 1117 Budapest, Pázmány Péter sétány 1/C. \\ "corresponding author: telbisztom@caesar.elte.hu
}

\begin{abstract}
The study of human-environment relationships in mountain areas is important for both theoretical and practical reasons, because many mountain areas suffer similar problems, namely depopulation, unemployment and natural hazards. Medium mountains constitute a special case within mountains because they are more populated but less attractive as tourist targets than high mountains. In this context, Apuseni Mts (Romania) is considered as a case study. In the present paper, we applied GIS-based, quantitative methods to characterize the strength and dynamics of human-environment interactions taking into consideration some environmental factors (elevation, relative height, slope, river distance, lithology, land cover, natural attractions) as well as historical population and recent tourism data. We found that population density has strong $\left(r^{2}>0.8\right)$ relationships with all relief factors (elevation, relative height, slope, river distance), and that best-fit functions are nonlinear. We outlined the varying demographic scenarios by elevation zones and interpreted the historically switching sign of population change versus elevation relationship. We proved that lithology, too, has an impact on the spatial distribution of population, though it is not independent from the relief effect. The land cover of that mainly cultural landscape is very strongly correlated with relief parameters (especially slope) that suggests a good adaptation. We pointed out the dominance of karst objects in the natural tourist potential of Apuseni Mts and explored further components (spas, heritage, towns) of real tourism as well. Finally, we concluded that the studied environmental settings in fact constrain the spatial framework of society, but socio-economic changes in history can be explained from the side of society, which conforms the theory of cultural possibilism.
\end{abstract}

Keywords: human-environment relations, Apuseni Mts, GIS, possibilism, tourism, karst

\section{Introduction}

People living in mountain areas face challenges day by day. Relief, harsher climate and natural hazards constrain the land that is suitable for settling and cultivation, however possibilities are also given in the form of mineral resources, better hydrologic conditions and nowadays by tourism. The habitability of mountain areas depends on the given climate zone, the elevation and ruggedness of the mountain and biogeographical domain. However, all of these settings only partly determine human establishment, because it is influenced by the changing human-environment interactions as well. Human-environment relationships have always been in the centre of geographical thinking. At the beginning of the 20th century geographical determinism was the mainstream theory due to the works of Ratzel and Huntington, but later on it was replaced by the cultural possibilism of Sauer and other theories with varying approaches of human-environment relationships (cf. Judkins et al. 2008; Brondízio and Moran 2013; Köszegi et al. 2015). Nowadays, neo-determinism has again got some popularity (Diamond 1997), but its acceptance is strongly critiqued (Sluyter, 2003; Judkins et al. 2008). Feng et al. (2007) stated that the spatial characteristics of rural settlements in mountainous areas reflect the condition of the natural environment and regional socio-economic development. Thus, the spatial pattern of population in mountainous areas can not be explained solely by natural or solely by socio-economic factors.

In the recent decades, the amount of data increased exponentially due to the information revolution that provides a possibility to explore new quantitative relationships. This type of research is less synthesizing, instead it focusses on certain elements of the human-environment relationships (e.g. population patterns). The GISbased, quantitative study of these relationships is a modern methodological approach (Cohen and Small 1998; Meybeck et al. 2001; Song et al. 2007; Patterson and Doyle 2011), and as Small and Cohen (2004) stated „,a necessary first step to understanding the spatial distribution of the population is to quantify its relationship to other factors that may influence it". Thus, we also join this approach and used GIS-based statistical analysis of human-environment interactions in our earlier works (Telbisz et al. 2014, 2015) and in the present paper, too. This way, we are able to numerically express the strength of the relationships and the temporal changes as well. Therefore, our aim is not to elaborate a comprehensive analysis of all elements of human-environment relations, but to explore those relationships that can be studied by the GIS methodology. The scale of human-environment studies changes from global (e.g. Meybeck et al. 2001; Cohen and Small 1998; Song et al. 2007; Patterson and 
Doyle 2011) through regional (e.g. Song et al. 2007; Feng et al. 2007; Ding et al. 2014; Telbisz et al. 2014) to local (e.g. Li et al. 2013; Huber et al. 2015). Whereas global and regional studies usually rely on statistical and GIS data, local (household) scale studies often use semi-structured interviews. However, different scale studies can not be considered as substitutes but rather as compliments.

Nevertheless, the study of human-environment relationships is important not only for theoretical reasons, but also from management point of view, since there are typical problems concerning mountain areas (e.g. depopulation, unemployment, natural hazards; as mentioned by Pejnovic and Husanović-Pejnović 2008, Milošević et al. 2010, 2011, Telbisz et al. 2015, Constantin et al. 2015, and many others). The first step to elaborate a good management is the exploration of problems, and after recognizing problems, several countries concluded to give mountain areas a special status in law, budget and development plans (Castelain et al. 2006; Pantic 2015).

Here we emphasize that medium mountains constitute a special case within mountain areas. Although English literature rarely discusses medium mountains separately (Price, 1986), they occupy extended areas in Europe, and they are frequently mentioned in German („Mittelgebirge”), French („moyennes montagnes”) or other European geographical studies. Medium mountains are sometimes defined by their elevation, but the essence is that their upper level does not reach the treeline and that they were not glaciated during the Quaternary. These facts determine much of their geomorphological, hydrological and biogeographical properties. Thus, medium mountains provide relatively better conditions for human settling, but they are usually less attractive from the viewpoint of modern tourism.

The Apuseni Mts (Romania, part of the Carpathians) with their $16,730 \mathrm{~km}^{2}$ area, have diverse relief and geology that provide a good opportunity to study the variability of human-environment relationships. This is why the Apuseni Mts were the subject of several recent geographical papers studying the relationship of people and their environment in both local and regional scale (e.g. Abrudan and Turnock 1999; Surd and Turnock 2000; Buza et al. 2001; Boțan 2010; Tătar 2013). Cocean (2001) pointed out the importance of karst terrains in the environmental system of Apuseni Mts. Demographic changes of the area have been studied by Drăgan (2010).

In the present paper, our aim is to examine the dynamics of the relationships between some selected environmental factors (relief and its derived parameters; land cover; natural attractions) and population in the regional context of Apuseni Mts, taking into consideration population data since the end of the 19th century and tourism data from the 21 st century. Tourism data were selected because it may be a very important element of the future of people living here.

\section{Data and Method}

Delineation of the study area was carried out basically according to the natural boundaries of Apuseni Mts, but the precise borders were adjusted to the administrative units (communes). In order to perform the regional scale quantitative analysis we created an integrated GIS database using the following data:

- Relief (the NASA SRTM digital terrain model (DTM), for further details see Rabus et al. 2003; Figure 1). Its horizontal resolution is cca. $90 \mathrm{~m}$, which is suitable for the scale of the present study. Slope values were derived from the DTM using standard GIS methods. Here we note that slope values calculated from $90 \mathrm{~m}$ resolution pixels are slightly less than real values (Kienzle 2004). Further on, relative elevation (,height” in the followings) was calculated as the difference between the actual elevation of a given pixel and the elevation of the lowermost point in the $5 \mathrm{~km}$ neighbourhood of that pixel.

- Geology (based on the 1:200,000 scale geological maps of Romania; Figure 2). After digitizing these maps, we categorized the lithological units by age and main rock type into Quaternary (Q) sediments, Tertiary (T) sediments, Mesozoic (M) sediments, Paleozoic (P) sediments, Plutonic, Volcanic, and Metamorphic rocks. Besides, we separeted terrains with karstic, partly karstic and nonkarstic rocks taking into consideration the hydrogeologic description of Apuseni Mts (Orăşeanu and Iurkiewicz 2010).

- Drainage network: rivers and streams were digitized from topographic maps and locally significant rivers were selected. We consider a river significant if it has a relatively large valley with higher level roads and occasionally railways. Thereafter, using GIS methods we determined for each pixel the Euclidean distance to the closest selected river (this value is called ,river distance” in the followings; Figure 3).

- Land cover data originate from the 1:100,000 scale European Corine CLC2006 database. This database is the result of a joint project of European countries. Corine was planned to provide quantitative, reliable and comparable land cover data for the member countries. Data collection was based on the manual interpretation of ortho-corrected SPOT-4 and/or IRS LISS III satellite images. The CLC apply 44 land cover classes in 3 hierarchical levels (Büttner et al. 2004, 2010). We simplified these categories by omitting the missing classes and unifying similar categories. The final classification used in this study included the following classes: arable lands, artificial surfaces, bare surfaces, complex agriculture, forests, grass and shrub areas, mines, pastures, water (Figure 4). 
- Population data for each settlement. The last census data (2011) comes directly from the National Institute of Statistics of Romania, whereas the data of earlier Hungarian and Romanian censuses (1880; 1890; 1900; $1910 ; 1920 ; 1930 ; 1941 ; 1956 ; 1966 ; 1977 ; 1992 ; 2002)$ were gathered from the summarizing work of Varga (2002). Here we mention that the Apuseni Mts belonged to Hungary before the Paris (Versailles) Peace Treaty in 1920. There were several country border changes during the 2 nd world war, but after the war, the 1920 state was restored, which means that the whole study are belongs to Romania since then. Besides, there is one important inhomogeneity in the data: the small sized, scattered settlements were declared separated units after the 2nd world war, that resulted a cca. 50\% increase in the (virtual) number of settlements, and also a (virtual) increase in the population number of the mountain areas since the new, separated units were found mainly at higher elevations. This fact is very important in the interpretation of data.

- Tourism data (the number of overnight stays from 2001 to 2014) is also from the National Institute of Statistics of Romania. Data are about the tourism accommodation establishments with an existing capacity of 5 bed-places and more. The identification of natural attractions was based on the tourist maps covering the area, and partly on our field experience. Map scales were mostly between 1:30,000 and 1:60,000 except some touristically ignored parts, where the best map is of 1:100,000 scale. We marked each and every point, which can be considered a natural attraction (panorama point, spectacular rock, cave, waterfall, etc.). We categorized them into 4 categories based on their significance (1-local, 2-regional, 3-national, 4-international significance) and determined if they are on karst or not.

Based on the GIS database, we calculated the population centroids (by elevation, by height, by slope, by river distance) and depicted their changes. We classified raster type environmental data (elevation, height, slope, river distance) into defined interval zones and calculated statistics (total number of people and settlements, population and settlement density, land cover proportions) for each zones. Elevation and height class intervals are $50 \mathrm{~m}$, slope intervals are $1^{\circ}$, and river distance intervals are $1000 \mathrm{~m}$. Thereafter, we used linear and nonlinear regression analysis in order to study the relationships between different factors.

\section{Results}

The total study area is $16,730 \mathrm{~km}^{2}$. The elevation of Apuseni Mts ranges from $105 \mathrm{~m}$ to $1849 \mathrm{~m}$ (asl), the most extended zone being between $350 \mathrm{~m}$ and $400 \mathrm{~m}$. Upwards from this level the surface extension (i.e. pixel frequency) decreases logarithmically. The climate is continental at the lower levels and mountainous in the higher terrains. The annual mean temperature varies between $11.0^{\circ} \mathrm{C}$ to $4.3^{\circ} \mathrm{C}$, whereas the annual sum of precipitation changes from $531 \mathrm{~mm}$ to $1134 \mathrm{~mm}$ as a function of elevation.

There are 1381 settlements (in 181 communes) and 658,954 people live in the study area, thus the mean population density is 39.4 people per $\mathrm{km}^{2}$. The size of settlements is well characterized by the fact that 477 people is the mean settlement population, moreover, as the population distribution by settlement is lognormal, the median settlement population is even smaller, 178 people. The largest town within the study area is Alba Iulia (55,924 people), but the most important, larger cities (Cluj Napoca, Oradea, Arad), which exert a strong influence on the people of Apuseni Mts are already outside the study area.

\subsection{Population versus relief and time}

We selected four parameters in connection with relief, which are not fully independent from each other, but they characterize the surface in different ways. The most often used parameter is elevation, which implies differences mainly in climate. The slope expresses the terrain ruggedness, which has a strong impact on building or cultivation potentials. The height is also in connection with ruggedness and denotes transport difficulties with a vertical dimension. Finally, river distance reflects the remoteness of a given settlement, the distance to the main arteries of transport.

We examined the relationship strength between the above factors and settlement and population density (Table 1). As we are interested not only in the actual relationship, but in the temporal changes as well, we calculated determination coefficients $\left(r^{2}\right)$ using all 13 census data. The results demonstrate relatively strong correlations with all 4 parameters and it is observed that temporal changes in $r^{2}$ exist, but are usually relatively small within this time range (except elevation vs settlement density, and slope vs settlement density). The type of best-fit function is nonlinear for all cases, but it is varied according to the studied relationship. Further on, the function type is generally stable in time for a selected relationship. Settlement density can be best modelled by height. However, its correlation with elevation is rather weak due to the fact that there is a special landscape in the heart of Apuseni Mts, the Land of Moţi (Figure 1), which is an area with lots of tiny, scattered settlements found at high elevation. Population density has similarly good correlations with all relief parameters, Up to 1966, slope and height (i.e. terrain ruggedness) result slightly better correlations, but since 1977, river distance (i.e. remoteness) has the strongest correlation with population density. 
The temporal population changes are presented in Figure 5. As for the total, we see an increase at the end of the 19th century. This trend is cut by the 1st world war, but afterwards it is compensated, the increase is prolonged up to the 2nd world war, and total population peaks in 1941. After the 2nd world war, there is a slower rate, fluctuating decrease, then after the political change of regime in 1990 a faster reduction of population occurs. Nevertheless, this total is the integration of varying population histories at different elevation zones. Thus, we examined population changes in each $100 \mathrm{~m}$ interval elevation class. This approach pointed out that long-standing, significant population increase took place only in the nearly lowermost 200-300 $\mathrm{m}$ zone. In this zone, the most remarkable growth occurred during the last two decades of the communist regime, but later on, it was followed by a drastic decline. In all other elevation zones up to $800 \mathrm{~m}$, growth is observed only till 1910 , and after the decline of the 1st world war this population level was hardly restored by 1941 . Thereafter, a slightly fluctuating, but more or less uniform rate population decrease can be observed. As for the zones upper than $800 \mathrm{~m}$, their situation is somewhat special, because an abrupt increase occurred between 1941 and 1956. However, this change is only virtual, it is connected to the administrative reform mentioned in the Data and Method chapter. Till 1941, the population living at higher elevations were attributed to their lower elevation communal centers, but since 1956 they are counted where they really live. During the last two decades of the communist regime, there was an intense (and real) decline, but a slower rate decrease continued in the postcommunist era. It clearly demonstrates how the population flowed from upper to lower parts of Apuseni Mts in the two decades before the change of regime, and how people moved outside the Apuseni Mts to larger cities and even abroad after the change of regime. The aforementioned changes are properly reflected in the movement of population centroids (Figure 6) as well. It is observed that before 1941, population centroids were relatively stable, i.e. the natural increase and migration balance of the higher terrains were of similar order than population increase of lower terrains. Then the administrative inhomogeneity between 1941 and 1956 is clearly recognizable in the elevation and height centroids, but not in the slope and river distance centroids. The reason is that even on the higher terrains, the settlement locations are on low-slope areas, and that due to the upstream part of Arieş river in the Land of Moţi, river distances are also small. However, from 1966, the population centroids moved at faster, while after 1990 at slower rate towards terrains, which are lower, less rugged, smaller in height and closer to significant rivers.

Population change rates were also calculated (Table 2). These rates have moderate or weak correlations with elevation, but the most important observation is the switching sign of correlation. The strongest positive correlation ( $r=0.59)$ refers to the period between 1900 and 1910, when the population of higher elevations had higher growth rates, marking an extensive period, when mountains were increasingly used by humans. (In fact, the 1956 correlation is even higher, but it is the result of the aforementioned administrative inhomogeneity.) The strongest negative correlation $(r=-0.84)$ portrays the one and a half decade before the change of regime, when higher terrains' population strongly declined. This is the period of withdrawal, when better life conditions (due to mining revenues, urban services) attracted people to move downwards. Therefore, it is argued, that socioeconomic changes are influenced by relief, but the way of impact changes with time, which means that it is dependent on the actual social situation. An observation that is in agreement with the thinking of cultural possibilism.

\subsection{Population versus lithology}

The geological units and the corresponding population and settlement statistics are shown in Table 3. Although only $15 \%$ of the total area is covered by Quaternary sediments, $68 \%$ of the population live on these terrains, consequently the population density is relatively high there (180 people per $\left.\mathrm{km}^{2}\right)$. The other end of the spectrum are the magmatic (plutonic and volcanic) terrains where population density is lower than 7 people per $\mathrm{km}^{2}$. However, this low density may be also the result of the fact that magmatic rocks are mostly found at higher elevations. Population density of karst terrains is similarly low ( 8.4 people per $\mathrm{km}^{2}$ ). Further on, if population densities are compared for each $50 \mathrm{~m}$ interval elevation class it is found that population densities of karst terrains are the lowest in almost all classes (except 3 zones), and their population density is only $41 \%$ of the population density of nonkarst terrains on the average.

Settlement density values are less extreme. It is due to the fact that even the rarely inhabited terrains have relatively large number of settlements, though these settlements have usually few inhabitants only. Here we note that even the geological settings are not independent from relief, as the more cultivable, Quaternary sediments are basically found at lower elevations (and heights) near the rivers, thus the geological impact in some way amplifies the relief effect.

\subsection{Land cover versus relief}

The land cover is influenced by nature in varying degree, but when a cultural landscape is considered (as in the case of Apuseni Mts), the human impact is very high, and land cover reflects how the humans utilize the 
landscape (e.g. Zhang et al. 2003; Mao et al. 2014). Thus, the relationships between land cover proportions and relief parameters also demonstrate the strength of human-environment interactions. A strong correlation reflects good adaption of humans to environmental conditions.

The land cover of Apuseni Mts is distributed among the following categories: half of the study area is covered by forests, on $17 \%$ there are pastures, while arable lands occupy only $12 \%$, complex agriculture $11 \%$, artificial areas 5\%, grass \& shrub $4 \%$, and all other categories are neglectable. We determined determination coefficients $\left(r^{2}\right)$ between these land cover categories and relief parameters using several function types (linear, exponential, logarithmic, power, 2nd or 3rd order polynomials; Table 4; Figure 7). The relationships proved to be very strong in most cases $\left(r^{2}>0.9\right.$, except with river distance), which testifies that landuse in the Apuseni Mts is well adapted to relief conditions. Most categories (arable lands, artificial lands, complex agriculture, forests) have the highest correlation with slope, but the grass \& shrub category is determined the best by height, and pastures by elevation. 2nd order polynomial functions describe relationships where an optimal value exists, i.e. as the given relief parameter gets higher or lower than this value, the proportion of the given land cover proportion is decreased. Or just the opposite is true (Figure 7). An example for the optimum value type is the proportion of forests, whose optimal slope angle is cca. $30^{\circ}$, or the pastures with a peak at $800 \mathrm{~m}$ elevation. Another example for the opposite (i.e. local minimum) type is the proportion of complex agriculture with a minimum at $35^{\circ}$. This latter is surprising at first and is due to the fact that complex agriculture has a growing proportion in the steeper slope categories, which is the in connection with the intensive landuse management of the dissected terrain at the Land of Moţi.

\subsection{Tourism potential of natural attractions versus real tourism}

The lookup of potential natural attractions in tourist maps resulted 599 objects, and $81 \%$ (487 objects) of them was of karstic origin (Figure 8). This high proportion is especially large if one takes into account that karstifiable rocks present only 6\% of Apuseni Mts. The most significant, internationally reputed attractions (Cheile Turzii, Padiş Plateau, Piatra Secuiului) are all karstic objects. Based on the above results, it is stated that karsts are of outstanding importance from the viewpoint of nature-based tourism. At least if the potential is considered. This is in agreement with the results of other researchers who pointed out that the geomorphological, geological and hydrological heritage of karstlands provide an important tourism potential (e.g. Kiernan 2011; Simić et al. 2014).

Thereafter we examined the spatial distribution of real tourism using the number of overnight stays (Figure 9). The statistics show that today, the number of overnight stays is at a similar level than in the first year of this century (2001). Before the 2008 economic crisis, there was a prosperity (partly due to the EU joining of Romania in 2007), followed by a drawback, and a compensation later on.

The spatial distribution of real tourism only partly overlaps the karst terrains, and there is no correlation between the number of overnight stays and the number of karstic objects at the commune level. However, the list of the most important tourist targets (Table 5) helps to explore the reasons of attractivity. Of course, towns have and advantage when absolute numbers are considered, but if the overnight stays per capita is taken into account, the natural attractions become more obvious. An important fact that both lists are headed by spas (Moneasa, Geoagiu), which are also connected to favorable hydrogeological (and partly karstic) settings. Here we note that Geoagiu was a notable spa even in the antiquity (Figure 10). The per capita statistics clearly demonstrate the significance of mountain location and of karst in tourism.

Nonetheless, it should be noted that the overnight stays statistics include only tourism accommodation establishments with an existing capacity of 5 bed-places and more. Furthermore, our field experiences and booking web sites also suggest that official statistics underestimate the real number of tourists. Discount accomodations (tourist chalets, guestrooms) probably provide less reliable data than larger hotels. However, the spatial distribution, which is important to us, reflects the real picture notwithstanding the above minor distortion, and communes with high numbers of overnight stays are in accordance with the well-known tourist targets. Besides, we emphasize that a significant number of tourists stay in the neighbouring larger cities (Cluj Napoca, Oradea, Arad), which are located outside the study area and visit the Apuseni Mts natural attractions in one day trip programs.

\section{Discussion}

In order to correctly interpret the above statistical results describing the relationships of environmental and social factors, it is necessary to briefly take into account the changing social and historical context of the Apuseni Mts. Three important natural settings can be highlighted that provided (or still provide) the economic bases of people living in the Apuseni Mts, though their proportions were variable during different periods of history. First, we mention the landscape itself, which is the base of the traditional subsistence agriculture, second, the mineral resources, and third, the natural monuments as targets of tourism. 
The society as a landscape forming agent was the most effective traditionally due to the variegated local agricultural activities and the high density, sporadic settlements. Permanent, small communities are widespread in the Apuseni Mts, and taking into account the seasonal, summer shepherding as well, it is concluded that an extended area and a large vertical range is populated in these medium mountains. As for the higher terrains, we can mention the denudation surfaces, which are relatively flat, thus they are favorable for seasonal or permanent settlements. Plateaus are especially typical for karstlands, but water scarcity may be a constraining factor. However, there are several mixed karsts in the Apuseni Mts, where water is available, therefore settlements could form on these terrains. The upper limit of permanent settlements is $1300 \mathrm{~m}$ a.s.l., which is mainly due to harsher climatic conditions above this level, so higher terrains, even if the relief is flat, are home to seasonal dwellings (of shepherds and foresters) only.

The traditional landuse management, which is the most typical in the Apuseni Mts for centuries, is characterized by a harmonic balance between grazing, complex agriculture around the houses and forest management. Notwithstanding some smaller, sporadic settlements, the human occupation of the mountainous area could probably begin in the Middle Ages due to the overpopulation and wars in the neighbouring basin territories. First, people settled at the bottom of valleys, then moved to higher terrains in the 18th-19th century (Ruşdea et al. 2005; Surd and Turnock 2010). As population increased, the people seeked to utilize the full agricultural potential, and they also tried to escape the increasing feudal charges by moving into the mountains. Thus, local shepherds (the so-called „moţi”) could live on the higher terrains beyond the effective reach of state administration. Later on, lumberers were also supported by landlords, who wanted to utilize their forests. The nuclei of high elevation, tiny settlements were the huts of lumberers and their families. Later on, they started to cultivate the land around the house, and as families grew, more houses were built near the first dwellings. This type of population increase and upward movement continued also in the period studied statistically in this paper, up to 1941.

The second important natural basis of economy in the Apuseni Mts is mining. It was already present in the antiquity (e.g. Roșia Montană: Roman gold mines), and after a long cessation, it became remarkable in the Middle Ages, when precious metals mined here contributed significantly to the economy of the Hungarian Kingdom. Small mining settlements were the foci of population in the mountains. Later on, the 19th century brought an economic growth in the country, but the relatively difficult access to the inner parts of Apuseni Mts caused a significant delay in the modernisation of the study area. Therefore, the real boom of local industry, principally of mining, took place only in the 20th century, when modern transport capabilities (railways and later, roads) were created (Boţan 2010). This relatively favorable process was interrupted by the world wars (both the 1st and 2nd), when not only the front crossed the area, but a significant proportion of men population was enrolled and died in the war. The emigration was also remarkable after the 1st world war.

The post 1945 reconstructions and the change to communist system created a new situation. The planned economy highly favored mining, that implied relatively better life conditions in the mining towns. These better conditions and urban services attracted the inhabitants of the higher elevation, scattered, agrarian settlements to move down into the valleys, at first periodically (commuting), later (by the next generation) permantly. This implied the depopulation of the higher elevation and remote settlements (Boțan and Ilovan 2006). Nonetheless, the partial results of the communist modernisation processes proved to be non-durable after the change to market economy in 1990. The key sector of local industry, the mining collapsed at one blow, and a number of settlements became severely disadvantaged locations. Therefore, not only the higher terrains but the valley settlements also began to decline and the emigration out of the Apuseni Mts increased (Constantin et al. 2015). Here we briefly mention the situation of Roșia Montană, where a large international project was initiated to reopen the gold mine, but environmental concerns (because of cyanidation technique and other reasons) were strongly articulated by environmental groups that prevented this project from being realised (at the moment). It is considered to be a milestone in the organisation of the Romanian civil society (Branea 2013).

A significant proportion of people (local stakeholders, scientists, and politicians alike) believe that tourism may help to come out from the post-communist economic crisis. It means that the third natural basis for living is (or could be) tourism in modern times. Based on this value, tourism - mainly inner tourism - highly increased after the change of regime (Cozma 2012). On the other hand, it implies that the traditional natural and cultural framework is gradually receding, though it is just one of the most attractive factor of local tourism (Linc et al. 2001). As demonstrated above, spas are the most valuable resources in the context of tourism today, but an important and still partly untapped possibility is connected to karst areas. Seemingly, it was recognized recently, and the infrastructure development has started, partly due to EU support. New asphalt roads leading to natural attractions have been built, caves were equipped with show cave facilities and the number of accomodation possibilities increased. However, it is only the beginning, and good marketing would be also necessary. Nonetheless, it still remains a question whether tourism will be capable to provide a solid basis for the maintain of population and for a sustainable development.

Due to the variegated geological settings and the high biodiversity of the area, the Land of Moţi is important for environmental movements as well. This, in turn, may lead to conflicts of interest in tourism 
development. Thus, it can be thought of as a sensitive system, and finding the balance is still a future task (Waack 2003; Serban and Touchart 2007).

As for tourism, it has a further notable basis as well, which is not of natural, but of cultural origin. Romanians living in the Apuseni Mts burst out several rebellions during the 18th and 19th century that became remarkable as a historical heritage for Romanian people (Tătar 2013). This heritage is combined with the fact the the remaining, still active mountain communities continue a traditional way of life close to nature, thus providing a basis for today's heritage and ecotourism (Surd and Turnock 2000). However, a ponderous question is, whether there remain people living in the tiny mountain settlements to continue this way of life, or the tourists arriving here can merely experience the phases of extinction (Figure 11).

We also compared our results to the global analysis of hypsographic demography. Meybeck et al. (2001) stated that ,population density at the global scale is not primarily linked to relief types”. It may be true globally, because the influence of climate variations as well as the proximity of seas may potentially overwrite relief factors. However, Small and Cohen (2004) came to partly contradictory conclusions: ,human population is more localized with respect to the physiographic parameters than with respect to the climatic parameters considered here". It demonstrates that global scale answers are not unambiguous. Thus, we do not want to extrapolate our results to global scale, but it is simply argued that regional studies have their merit in finding local humanenvironment relationships, and the real impact of relief factors can be better observed in the scale of our study, as climate is more homogeneous for smaller regions and as our study area is far from the coastlines. Another result of Meybeck et al. (2001) is that ,at the global scale, population density seems to be closely linked or proportional to water runoff'. It is more similar to our results, but while in the global context it is interpreted as access to water resources, in our study the river distance is more an expression of remoteness, i.e. the distance to the main transport pathways.

\section{Conclusions}

The GIS-based, quantitative analysis proved to be a useful tool in the exploration of the strength and dynamics of human-environment relationships. The advantage of regional studies with respect to global analysis is that the impact of certain environmental factors can be more obvious in smaller, more homogeneous units. Further on, even today, better resolution data of certain factors are available only in a regional scale, whereas worldwide geological, land cover or population databases are still of lower resolution or accuracy. Although the whole complexity of human-environment relations can not be explored purely by quantitative methods, the results of quantitative analysis should be taken into consideration in more complex studies, too. In the present research, we applied a GIS approach, that provides an opportunity to study the human-environment relations preferably from the direction of environment. Further methods (e.g. interviews, study of development projects, etc.) can be used to deepen the understanding of social dimensions but these are beyond the purpose of this study.

Using the Apuseni Mts as a case example of continental medium mountains, we found that environmental settings (namely elevation, relative height, slope, river distance, lithology, hydrography) have a relatively strong impact on the spatial distribution of human population and on land cover as well. This impact can be best described by nonlinear relationships. The best explaining factor for population density and for most land cover categories was the slope angle, i.e. terrain ruggedness.

One of the novel features of our study is that we used this quantitative approach for temporal changes as well. This way, we pointed out that the even if the relationships of a given moment are strong, there are changes in time, and for instance, the relationship of population change and elevation had a switching sign during the studied period. As the natural settings of the Apuseni Mts were more or less stable during the studied period, the changes can be explained from the side of society, which conforms the theory of cultural possibilism. Thus, we agree the views of Small and Cohen (2004), Feng et al. (2007), Ballinger (2011) and many others, who concluded that environmental and socio-economic factors should be analyzed together. Further conclusions from the present study are that remoteness can be an advantage in periods of social turbulance, but it is a disadvantage in the modern, centralized economy. Mining can produce higher revenues, but mineral resources may run out and mining often causes environmental problems, which survive the period of mining. Living on karst is usually more disadvantageous due to water scarcity and poor soil fertility, but it may offer a significant tourist potential in the modern world. Ultimately, it is concluded that although environmental settings constrain the spatial framework of society, conscious or unconscious decisions drive how the society utilizes the natural environment.

\section{Acknowledgements}

This research has been supported by the Hungarian National Science Foundation, OTKA 104811 project. The work of Tamás Telbisz has been supported by the János Bolyai Scolarship of the Hungarian Academy of Sciences. 


\section{References}

Abrudan I, Turnock D (1999) A rural development strategy for the Apuseni Mountains, Romania. GeoJournal 46: 319-336.

Ballinger C (2011) Why Geographic Factors are Necessary in Development Studies. Social Science Research Network: http://ssrn.com/abstract=1791127 p 41. DOI: 10.2139/ssrn.1791127

Boţan CN (2010) Ţara Moţilor. Studiu de geografie regională (The Land of the Moţi. Study of Regional Geography). Presa Universitară Clujeană, Cluj-Napoca. p 527.

Boțan CN, Ilovan OR (2006) Trends of Industrial Reconversion in the Land of the Moți. Romanian Review of Regional Studies 2(1): 113-120.

Branea C (2013) Models Of Contention and Participation af Civil Society in Roşia Montană Environmental Conflict. The Romanian Journal of Society and Politics 8(2): 87-113.

Brondízio ES, Moran EF (eds., 2013): Human-Environment Interactions: Current and Future Directions. Dordrecht, The Netherlands: Springer Scientific Publishers, p 434. DOI: 10.1007/978-94-007-4780-7

Büttner Gy, Feranec J, Jaffrain G, Mari L, Maucha G, Soukup T (2004) The CORINE Land Cover 2000 Project. EARSeL eProceedings 3(3): 331-346.

Büttner Gy, Kosztra B, Sousa A, Steenmans C (2010) CLC2006: Mapping Land Cover of Europe under GMES 26-34. In: Kalaitzidis C, Manakos I (eds.) Imagin[e,g] Europe: Proceedings of the 29th Symposium of the European Association of Remote Sensing Laboratories, Chania, Greece. p 460. DOI:10.3233/978-160750-494-8-26

Buza M, Dimen L, Pop G, Turnock D (2001) Environmental protection in the Apuseni Mountains: The role of Environmental Non-Governmental Organisations (ENGOs). GeoJournal 54: 631-653.

Castelein A, Dinh TTV, Mekouar MA, Villeneuve A (2006) Mountains and the Law. Emerging Trends. FAO Legislative Study 75, Rev. 1. Rome: FAO of the UN. p 91.

Cocean P (2001) Environment Threats in Romanian Karst. 13th International Congress of Speleology, Brasilia DF: 613-617.

Cohen JE, Small C (1998) Hypsographic demography: The distribution of human population by altitude. Proceedings of the National Academy of Sciences of the USA 95: 14009-14014. DOI:10.1073/pnas.95.24.14009

Constantin V, Ştefănescu L, Kantor CM (2015) Vulnerability assessment methodology: A tool for policy makers in drafting a sustainable development strategy of rural mining settlements in the Apuseni Mountains, Romania. Environmental Science \& Policy (52): 129-139. DOI:10.1016/j.envsci.2015.05.010

Cozma LT (2012): Északnyugat-Erdély helye és szerepe Románia turizmusában - realitások és kihívások. (The role of NW-Transylvania in the tourism of Romania - reality and challenges.) In: Nyáry D (ed) VI. Magyar Földrajzi Konferencia, Szeged, pp 92-107.

Diamond J (1997) Guns, Germs, and Steel: The Fates of Human Societies. W.W. Norton \& Company, NewYork. p 460.

Ding MT, Cheng ZL, Wang Q (2014) Coupling mechanism of rural settlements and mountain disasters in the uppper reaches of Min River. Journal of Mountain Science 11(1). DOI: 10.1007/s11629-012-2366-x.

Drăgan M. (2010) Multi-scale Analysis of the Demographic Evolution in the Apuseni Mountains between 1880 and 2008. Romanian Review of Regional Studies 6(1): 57-66.

Feng W, Li A, Zhou W (2007) Spatial Pattern of Rural Settlements in the Upper Reaches of the Minjiang River - a Case Study in Maoxian County, Sichuan. Journal of Mountain Science 4/2: 146-154. DOI: 10.1007/s11629-007-0146-9

Huber FK, Morlok M, Weckerle CS, Seeland K (2015) Livelihood Strategies in Shaxi, Southwest China: Conceptualizing Mountain-Valley Interactions as a Human-Environment System. Sustainability 7: 32043229. DOI: $10.3390 / \mathrm{su} 7033204$

Judkins G, Smith M, Keys E (2008) Determinism within human-environment research and the rediscovery of environmental causation. The Geographical Journal 174 (1): 17-29. DOI: 10.1111/j.14754959.2008.00265.x

Kienzle S (2004) The Effect of DEM Raster Resolution on First Order, Second Order and Compound Terrain Derivatives. Transactions in GIS 8(1): 83-111. DOI: 10.1111/j.1467-9671.2004.00169.x

Kiernan K (2011): Challenges For Environmentally Sustainable Development Of Natural Resources In The Nam Ou Karst, Northern Laos. Acta Carsologica 40(2): 341-355.

Köszegi M, Bottlik Zs, Telbisz T, Mari L (2015) Human-environment relationships in modern and postmodern geography. Hungarian Geographical Bulletin 64: 87-99. DOI: 10.15201/hungeobull.64.2.1

Li YR, Liu YS, Long HL, Wang JY (2013) Local responses to macro development policies and their effects on rural system in China's mountainous regions: The case of Shuanghe Village in Sichuan Province. Journal of Mountain Science 10(4): 588-608. DOI: 10.1007/s11629-013-2544-5 
Linc R, Nistor S, Turnock D (2011) Aspects Regarding the Environmental impact of Tourism Activities in the Apuseni Natural Park (Romania). Analele Universitații din Oradea (Seria geografie) 21(2): 340-353.

Mao X, Meng J, Wang Q (2014) Tourism and Land Transformation: A Case Study of the Li River Basin, Guilin, China. Journal of Mountain Science 11(6): 1606-1619. DOI: 10.1007/s11629-013-2871-6

Meybeck M, Green P, Vörösmarty C (2001) A new typology for mountains and other relief classes: an application to global continental water resources and population distribution. Mountain Research and Development 21(1): 34-45.

Milošević MV, Milivojević M, Ćalić J (2010) Spontaneously abandoned settlements in Serbia, Part 1. Journal of the Geographical Institute Cvijić SASA 60(2): 39-57. DOI:10.2298/IJGI1002039M

Milošević MV, Milivojević M, Ćalić J (2011) Spontaneously abandoned settlements in Serbia, Part 2. Journal of the Geographical Institute Cvijić SASA 61(2): 25-35. DOI:10.2298/IJGI1102025M

Orăşeanu I, Iurkiewicz A (eds, 2010) Karst Hydrogeology of Romania, Belvedere, Oradea, p 443.

Pantić M (2015): Delineation of Mountains and Mountain Areas in Europe - a Planning Approach. Journal of the Geographical Institute Cvijić 65(1): 43-58. DOI: 10.2298/IJGI1501043P

Patterson LA, Doyle MW (2011) Hypsographic demography across scale. Professional Geographer 63(4): 514529. DOI:10.1080/00330124.2011.578534

Pejnović D, Husanović-Pejnović D (2008) Causes and consequences of demographic development in the territory of Velebit Nature Park, 1857-2001. Periodicum Biologorum 110(2): 195-204.

Price LW (1986): Mountains and Man. University of California Press, Berkeley and Los Angeles, p 507.

Rabus B, Eineder M, Roth A, Bamler R (2003) The shuttle radar topography mission - a new class of digital elevation models acquired by spaceborne radar. Photogramm. Rem. Sens. 57: 241-262. DOI: 10.1016/S0924-2716(02)00124-7

Ruşdea E, Reif A, Povară I, Konold W (eds, 2005) Perspektiven für eine traditionelle Kulturlandschaft in Osteuropa (Ergebnisse eines inter- und transdisziplinären, partizipativen Forschungsprojekt im ApuseniGebirge in Rumänien). Institut für Landespflege, Freiburg im Breisgau, p 401.

Serban G, Touchart L (2007) Un nouveau parc naturel autour d'un vieux lac artificiel: les enjeux d'une Roumanie en transition dans les monts Apuseni. Géocarrefour 82(4): 243-253.

Simić, S, Milovanović B, Jojić-Glavonjić T (2014) Theoretical Model For The Identification Of Hydrological Heritage Sites. Carpathian Journal of Earth and Environmental Sciences 9(4): 19-30.

Sluyter A (2003) Neo-Environmental Determinism, Intellectual Damage Control, and Nature/Society Science. Antipode 35(4): 813-817. DOI:10.1046/j.1467-8330.2003.00354.X

Small C, Cohen JE (2004) Continental Physiography, Climate and the Global Distribution of Human Population. Current Anthropology 45(2): 269-277. DOI:10.1086/382255

Song G, Li Z, Bao Y, Lü H, Gao J, Wang H, Xu T, Cheng Y (2007) Spatial distribution regularity and influence factors of population density in the LRGR. Chinese Science Bulletin 52(2): 90-97. DOI: 10.1007/s11434007-7027-z

Surd V, Turnock D (2000) Romania’s Apuseni Mountains: safeguarding a cultural heritage. GeoJournal 50: 285-304. DOI: 10.1023/A:1007170018729

Tătar CF (2013) Identity Encounters. Host-Guest Interactions in the Land of Moţi (Romania). GeoJournal of Tourism and Geosites 11(1): 66-74.

Telbisz T, Bottlik Zs, Mari L, Köszegi M (2014) The Impact of Topography on Social factors, a Case Study of Montenegro. Journal of Mountain Sciences 11(1): 131-141. DOI:10.1007/S11629-012-2623-Z

Telbisz T, Bottlik Zs, Mari L, Petrvalská A (2015) Exploring relationships between karst terrains and social features by the example of Gömör-Torna Karst (Hungary-Slovakia). Acta Carsologica (in print)

Varga EÁ (2002) Erdély etnikai és felekezeti statisztikája 1850-2002 (Ethnic and religion statistics of Transylvania 1850-2002). I-V. Pro-Print Kiadó, Csíkszereda. http://www.kia.hu/konyvtar/erdely/erd2002.htm

Waack Ch (2003) Tourism and Mining in the Apuseni Mountains - Contradictory Solutions for Regional Development in a Global Context. In: Ilieș A, Wendt J (eds.), Europe between millenniums: political geography studies. Editura Universitații din Oradea pp 245-255.

Zhang C, Day M, Li W (2003) Landuse And Land Cover Change In The Lunan Stone Forest, China. Acta Carsologica 32(2): 161-174.

\section{List of figures and tables}

Table 1 Determination coefficients $\left(r^{2}\right)$ between settlement density (SD), population density (PD) and relief parameters. Minimum and maximum values of the studied period (1880-2011) and the best-fit function type is given.

\begin{tabular}{|l|l|l|l|l|}
\hline & Elevation & Slope & Height & Riv.distance \\
\hline
\end{tabular}




\begin{tabular}{|l|l|l|l|l|}
\hline SD & $0.26-0.91(\exp )$ & $0.57-0.92(\exp )$ & $0.89-0.96(\ln$, pow $)$ & $0.73-0.80(\exp )$ \\
\hline PD & $0.79-0.87(\exp )$ & $0.81-0.89(\exp )$ & $0.78-0.91(\ln$, pow $)$ & $0.74-0.87($ pow $)$ \\
\hline
\end{tabular}

Table 2 Linear correlation coefficient $(r)$ between population change and elevation (1890-2011). *: statistically significant at the $5 \%$ level.

\begin{tabular}{|c|c|c|c|c|c|c|c|c|c|c|c|c|}
\hline year & 1890 & 1900 & 1910 & 1920 & 1930 & 1941 & 1956 & 1966 & 1977 & 1992 & 2002 & 2011 \\
\hline $\boldsymbol{r}$ & -0.39 & -0.43 & $0.59^{*}$ & -0.44 & 0.32 & 0.42 & $0.71^{*}$ & 0.47 & $-0.62^{*}$ & $-0.84^{*}$ & $-0.66^{*}$ & -0.37 \\
\hline
\end{tabular}

Table 3 Distribution of population and settlements according to geology (A: Area, P: population, S: Settlement, D: Density)

\begin{tabular}{|c|c|c|c|c|c|c|c|c|}
\hline Rock type & $\left.\mathbf{A} \mathbf{( k m}^{\mathbf{2}}\right)$ & $\mathbf{A ~ ( \% )}$ & $\mathbf{P}$ & $\mathbf{P}(\mathbf{\%})$ & $\left.\mathbf{P D} \mathbf{( k m}^{-2}\right)$ & $\mathbf{S}$ & $\mathbf{S}(\mathbf{\%})$ & $\left.\mathbf{S D} \mathbf{( k m}^{-\mathbf{}}\right)$ \\
\hline Q.Sediment & 2497 & $15 \%$ & 448861 & $68 \%$ & 179.8 & 461 & $33 \%$ & 0.185 \\
\hline T.Sediment & 3665 & $22 \%$ & 112244 & $17 \%$ & 30.6 & 251 & $18 \%$ & 0.068 \\
\hline M.Sediment & 3993 & $24 \%$ & 46738 & $7 \%$ & 11.7 & 344 & $25 \%$ & 0.086 \\
\hline P.Sediment & 419 & $3 \%$ & 3700 & $1 \%$ & 8.8 & 46 & $3 \%$ & 0.110 \\
\hline Plutonic & 1328 & $8 \%$ & 9089 & $1 \%$ & 6.8 & 44 & $3 \%$ & 0.033 \\
\hline Volcanic & 1747 & $10 \%$ & 10172 & $2 \%$ & 5.8 & 62 & $4 \%$ & 0.035 \\
\hline Metamorphic & 3081 & $18 \%$ & 28150 & $4 \%$ & 9.1 & 173 & $13 \%$ & 0.056 \\
\hline Karst & & & & & & & & \\
\hline Non-karst & 14232 & $85 \%$ & 616552 & $94 \%$ & 43.3 & 1213 & $88 \%$ & 0.085 \\
\hline Mixed karst & 1534 & $9 \%$ & 34306 & $5 \%$ & 22.4 & 125 & $9 \%$ & 0.082 \\
\hline Karst & 964 & $6 \%$ & 8096 & $1 \%$ & 8.4 & 43 & $3 \%$ & 0.045 \\
\hline Sum/Mean & $\mathbf{1 6 7 3 0}$ & $\mathbf{1 0 0 \%}$ & $\mathbf{6 5 8 9 5 4}$ & $\mathbf{1 0 0 \%}$ & $\mathbf{3 9 . 4}$ & $\mathbf{1 3 8 1}$ & $\mathbf{1 0 0 \%}$ & $\mathbf{0 . 0 8 3}$ \\
\hline
\end{tabular}

Table 4 Determination coefficients $\left(r^{2}\right)$ between land cover proportions and relief parameters with best-fit function types.

\begin{tabular}{|l|l|l|l|l|l|l|}
\hline & Arable & Artificial & Complex agr. & Forest & Grass\&shrub & Pasture \\
\hline Elevation & $0.90(\exp )$ & $0.90(\mathrm{exp})$ & $0.78($ lin) & $0.77($ poly) & $0.90(\mathrm{exp})$ & $0.91($ poly) \\
\hline Slope & $0.94(\mathrm{exp})$ & $0.96(\mathrm{exp})$ & $0.96($ poly 3rd) & $0.97($ poly) & no corr. & $0.45($ poly) \\
\hline Height & $0.92(\ln )$ & $0.90(\mathrm{exp})$ & $0.89(\mathrm{lin})$ & $0.92($ poly) & $0.96(\mathrm{exp})$ & $0.86($ poly) \\
\hline Riv.distance & $0.42(\ln )$ & $0.57($ poly) & $0.64($ poly) & $0.76($ poly) & $0.43($ poly) & 0.79 (poly) \\
\hline
\end{tabular}

Table 5 Tourist targets in the Apuseni Mts. Top list by the number of overnight stays and by the overnight stays per capita (data for year 2014). H: heritage, K: karstic, M: Mountain tourism, T: town with cultural attractions.

\begin{tabular}{|l|c|c|l|c|c|}
\hline \multicolumn{1}{|c|}{ Settlement } & $\begin{array}{c}\text { Overnight } \\
\text { stays }\end{array}$ & Attractions & \multicolumn{1}{|c|}{ Settlement } & $\begin{array}{c}\text { Overnight } \\
\text { stays per } \\
\text { capita }\end{array}$ & Attractions \\
\hline 1. Geoagiu & 133658 & spa, K & 1. Moneasa & 90.0 & spa, K \\
\hline 2. Moneasa & 84770 & spa, K & 2. Geoagiu & 23.5 & spa, K \\
\hline 3. Alba Iulia & 78336 & $\mathrm{~T}$ & 3. Arieseni & 10.9 & ski, M, K \\
\hline 4. Zalau & 38460 & $\mathrm{~T}$ & 4. Rimetea & 8.6 & $\mathrm{H}, \mathrm{M}, \mathrm{K}$ \\
\hline 5. Floresti & 22519 & $\mathrm{~T}(\mathrm{Cluj}$ satellite $)$ & 5. Belis & 3.7 & $\mathrm{M}$, lake \\
\hline 6. Arieseni & 19107 & ski, M, K & 6. Albac & 3.4 & $\mathrm{H}, \mathrm{M}, \mathrm{K}$ \\
\hline 7. Gilau & 10817 & $\mathrm{H}, \mathrm{M}, \mathrm{T}(\mathrm{Cluj}$ satellite $)$ & 7. Pocola & 3.1 & $\mathrm{M}, \mathrm{K}$ (cave) \\
\hline 8. Rimetea & 9282 & $\mathrm{H}, \mathrm{M}, \mathrm{K}$ & 8. Salciua & 2.8 & $\mathrm{M}, \mathrm{K}$ (cave) \\
\hline 9. Albac & 7461 & $\mathrm{H}, \mathrm{M}, \mathrm{K}$ & 9. Garda de Sus & 2.5 & $\mathrm{M}, \mathrm{K}$ (cave) \\
\hline 10. Aiud & 7183 & $\mathrm{~T}$ & 10. Intregalde & 2.3 & $\mathrm{M}, \mathrm{K}$ \\
\hline 11. Baciu & 5708 & $\mathrm{~T}(\mathrm{Cluj}$ satellite $)$ & 11. Baisoara & 2.2 & ski, M \\
\hline 12. Budureasa & 5257 & $\mathrm{M}, \mathrm{K}$ & 12. Vidra & 2.0 & $\mathrm{H}, \mathrm{M}, \mathrm{K}$ \\
\hline
\end{tabular}

Figure 1 Relief and settlements in the Apuseni Mts. Inset map shows the location of Apuseni Mts within Europe Figure 2 Simplified geology of the Apuseni Mts (Q: Quaternary, T: Tertiary, M: Mesozoic, P: Palaeozoic) 
Figure 3 River distance, road network and settlements in the Apuseni Mts

Figure 4 Land cover map of Apusent Mts (after CLC2006 data)

Figure 5 Population changes in the Apuseni Mts (1880-2011) as a total, and by $100 \mathrm{~m}$ vertical interval elevation zones. The right graph zooms to the upper elevation zones, note that the right population scale is 10-fold the left scale! Dashed line marks the administrative inhomogeneity of data between the censuses in 1941 and 1956. See text for further explanation.

Figure 6 Changing population centroids by elevation, slope, height and river distance. Dashed line marks the administrative inhomogeneity of data between the censuses in 1941 and 1956. See text for further explanation. Figure 7 Functional relationships between land cover proportions and relief parameters

Figure 8 The spatial distributions of natural attractions (with significance: 1-local, 2-regional, 3-national, 4international) and overnight stays (OS) per capita

Figure 9 Changes of overnight stays from 2001 to 2014

Figure 10 Remains of the antique spa in Geoagiu (photo Telbisz)

Figure 11 Abandoned traditional moţi house in an extinct settlement, Poieni in the Land of Moţi (photo Telbisz) 
Figure 1

$22^{\circ} 0^{\prime} E$

$22^{\circ} 30^{\prime} \mathrm{E}$

$23^{\circ} \mathrm{O}^{\prime} \mathrm{E}$

$23^{\circ} 30^{\prime} \mathrm{E}$

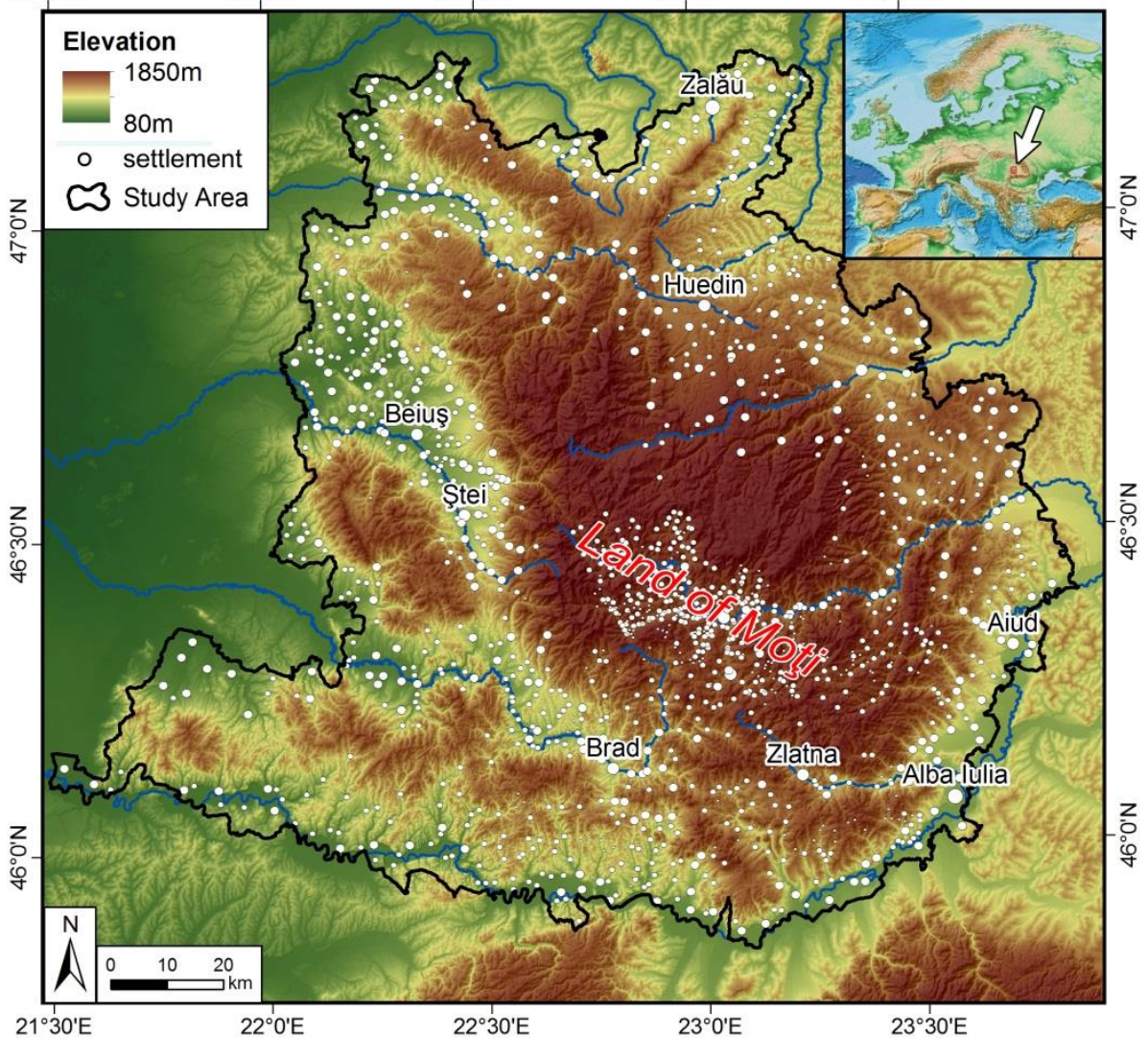

Figure 2

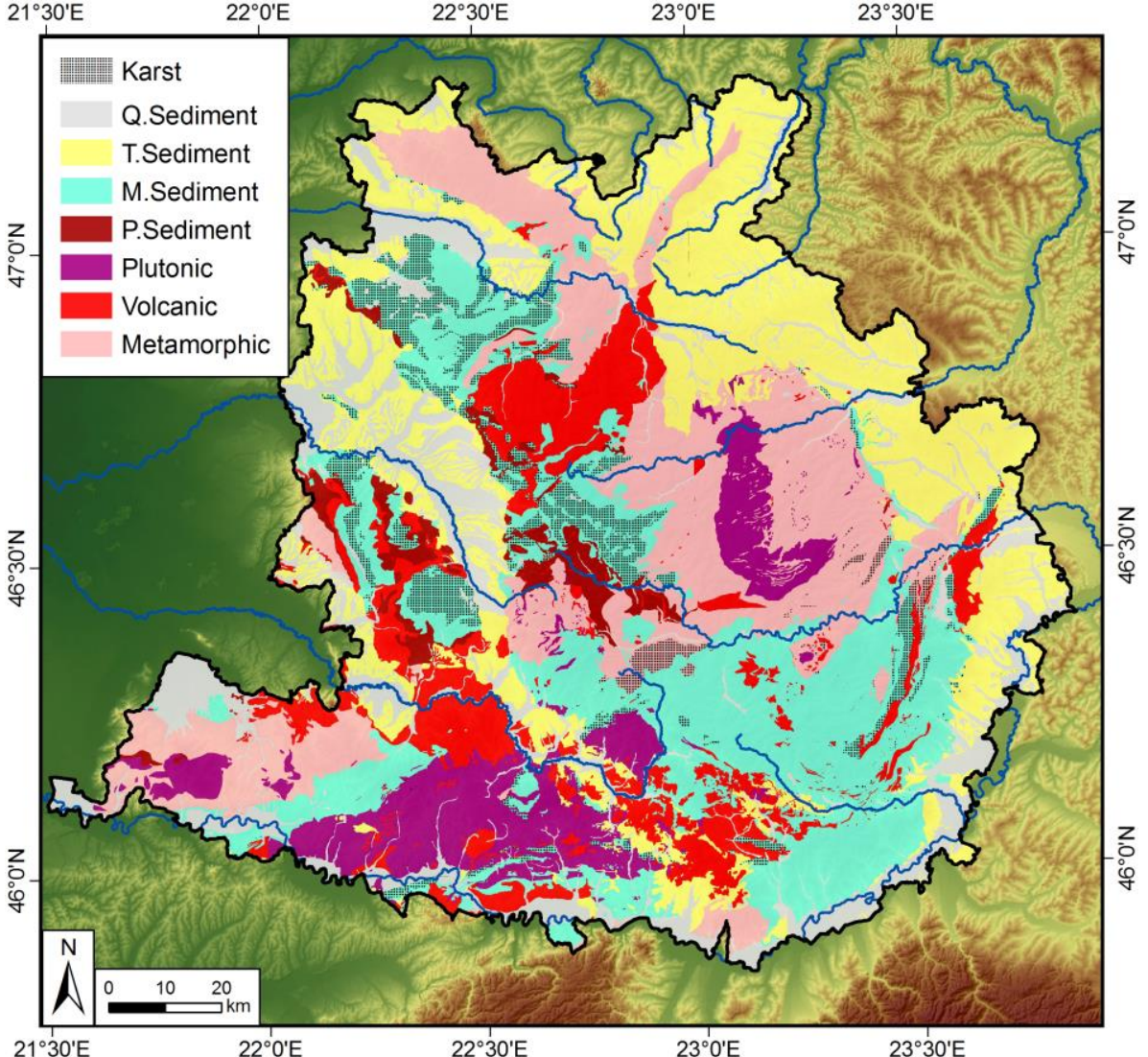


Figure 3

$22^{\circ} 0^{\prime} \mathrm{E}$

$22^{\circ} 30^{\prime} \mathrm{E}$

$23^{\circ} 0^{\prime} \mathrm{E}$ $23^{\circ} 30^{\prime} \mathrm{E}$

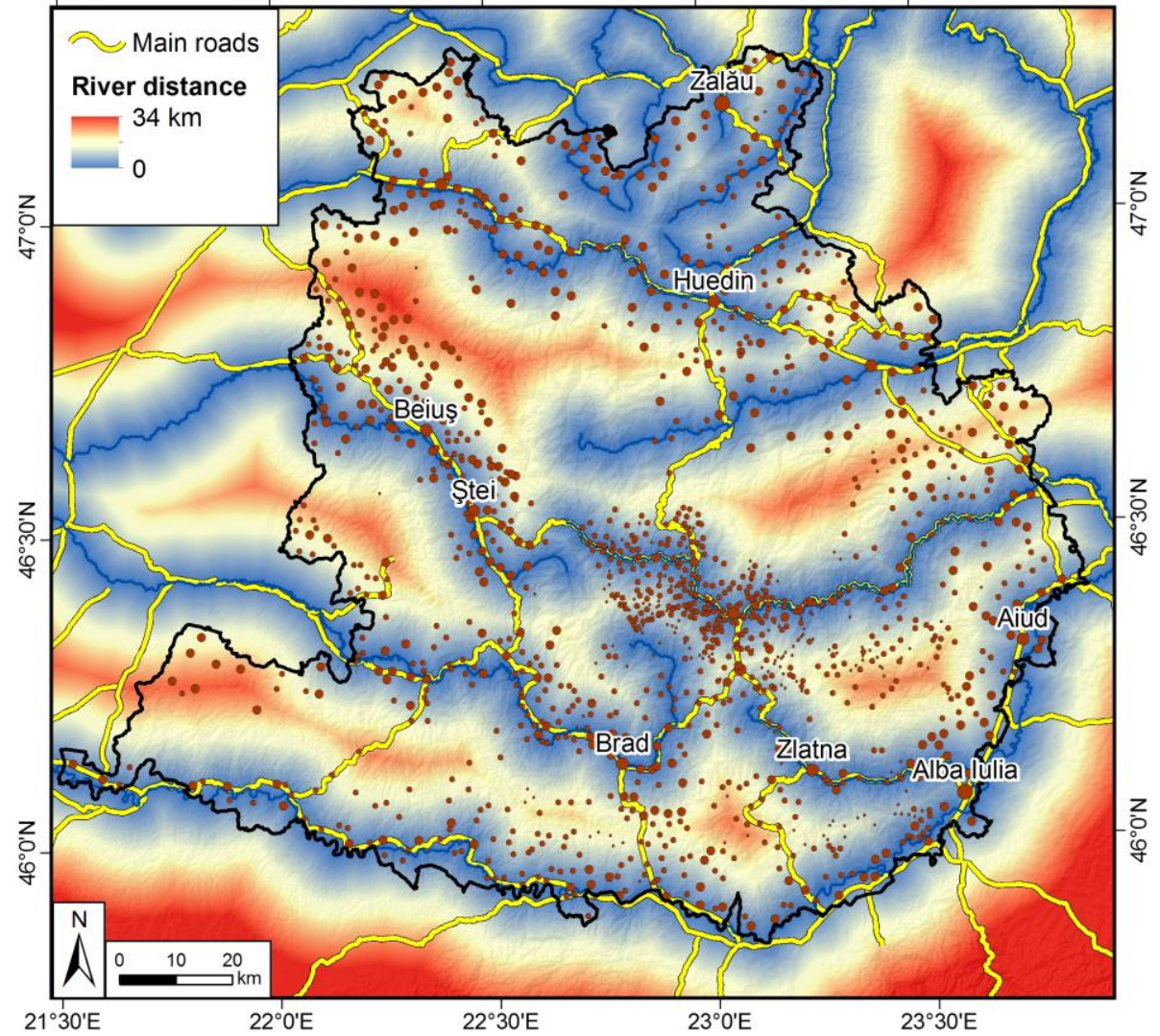

Figure 4

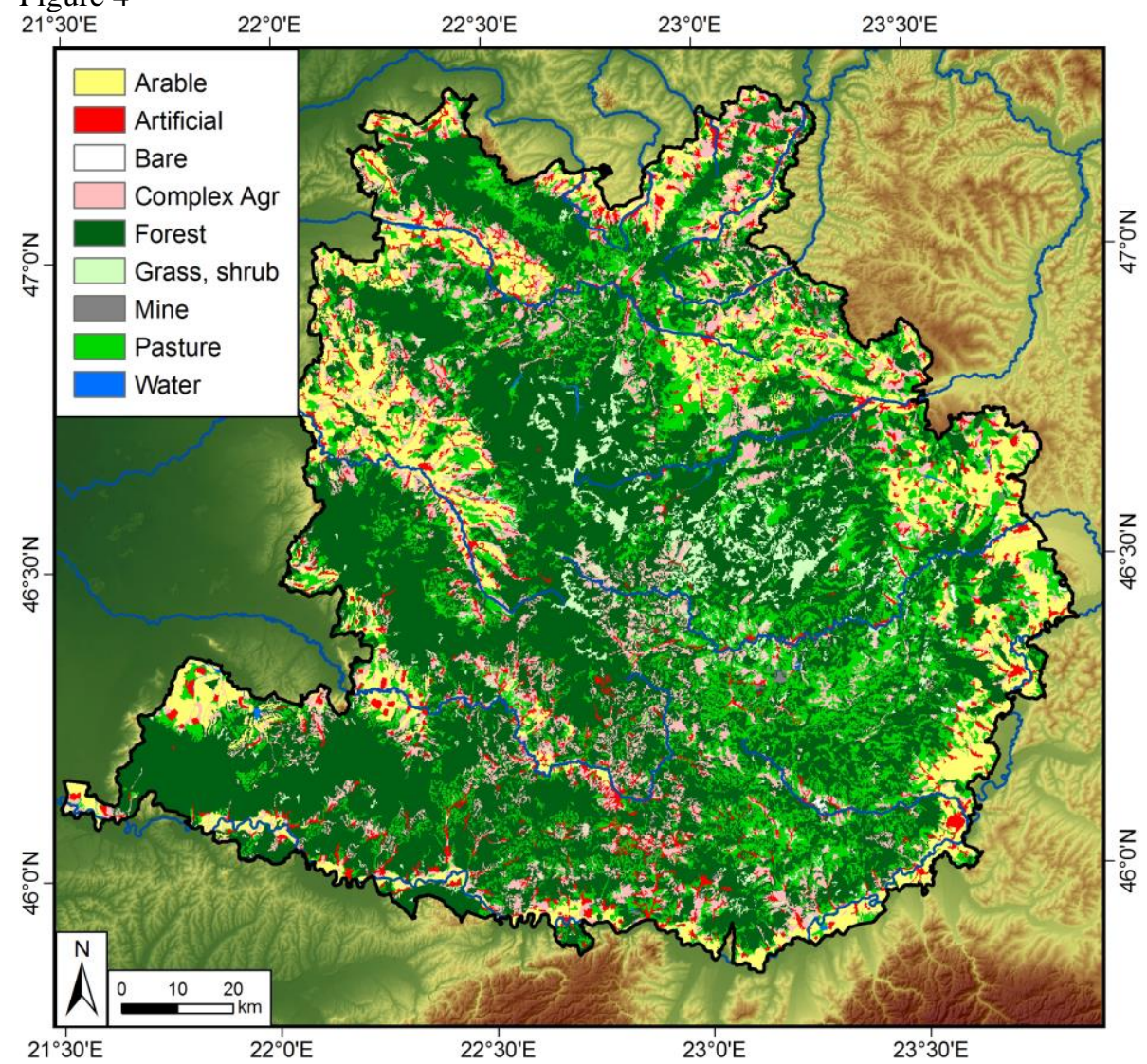


Figure 5

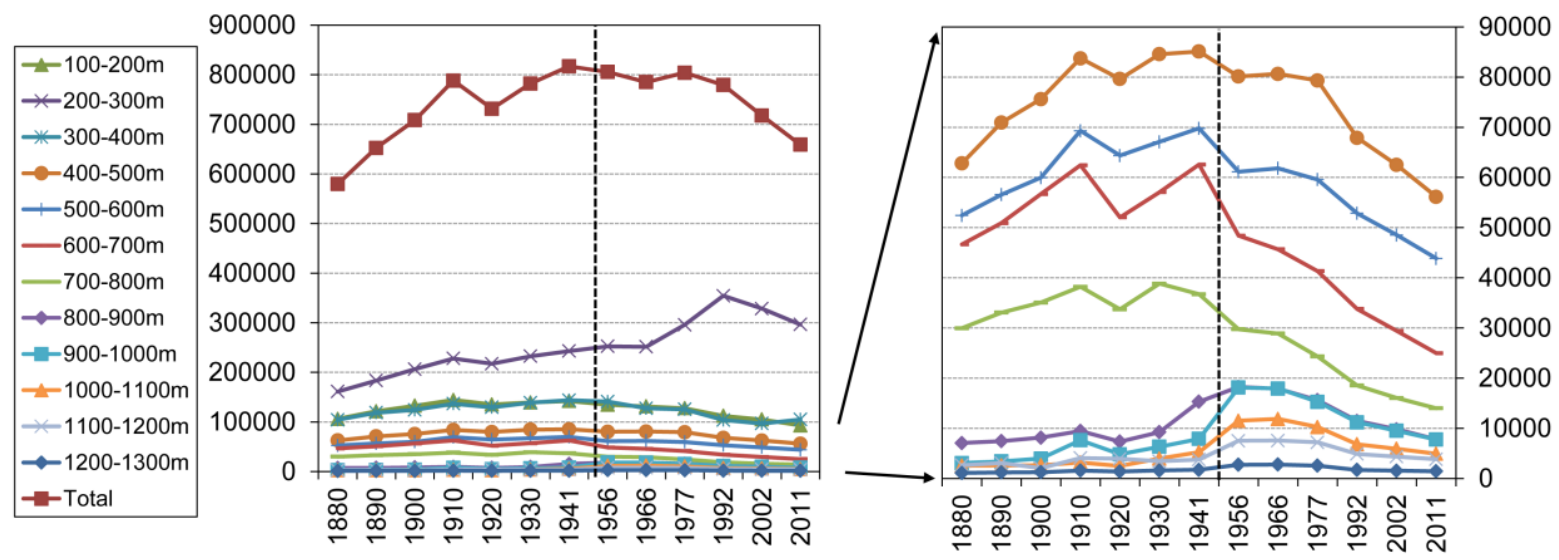

Figure 6

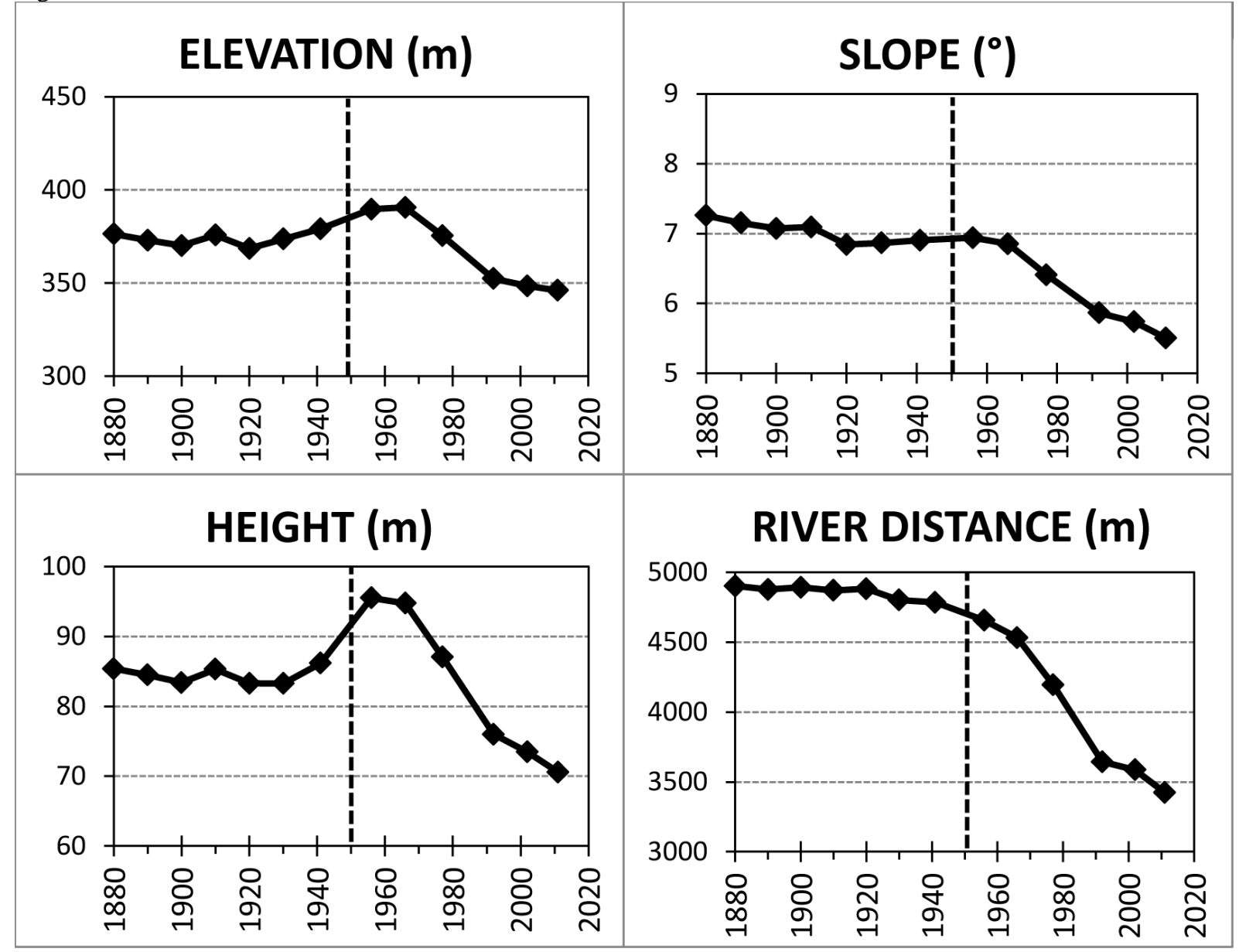


Figure 7

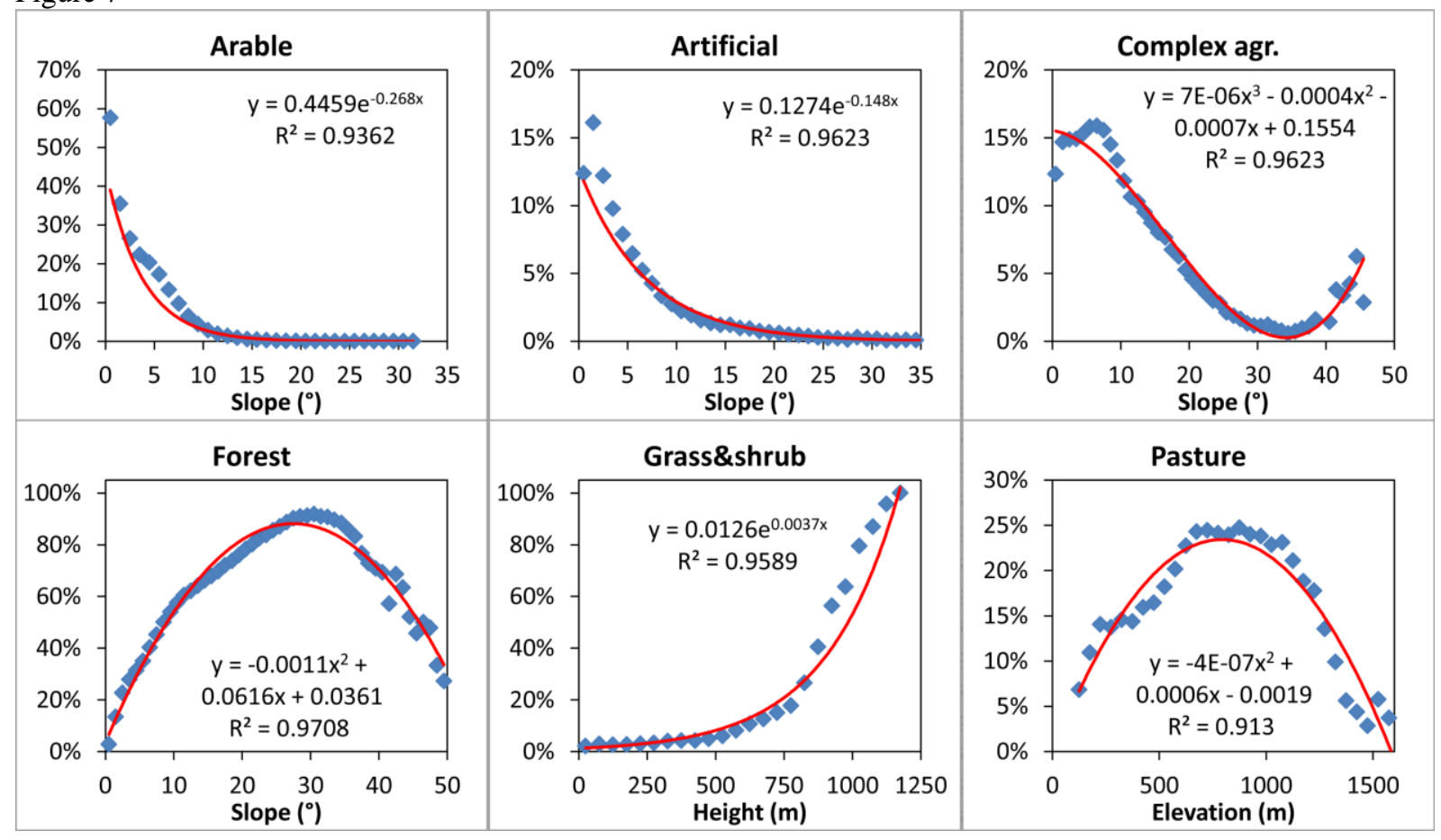

Figure 8

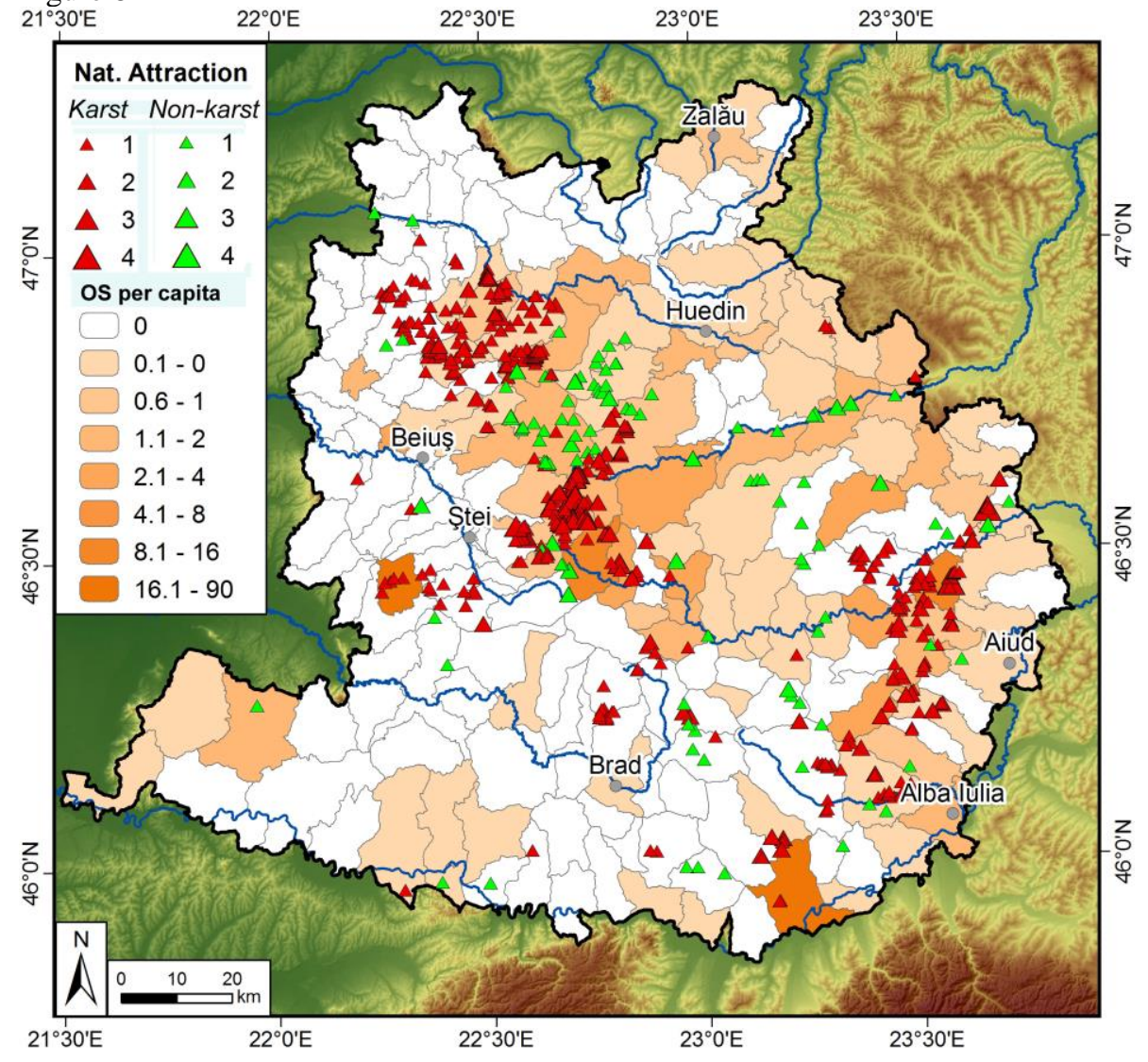


Figure 9

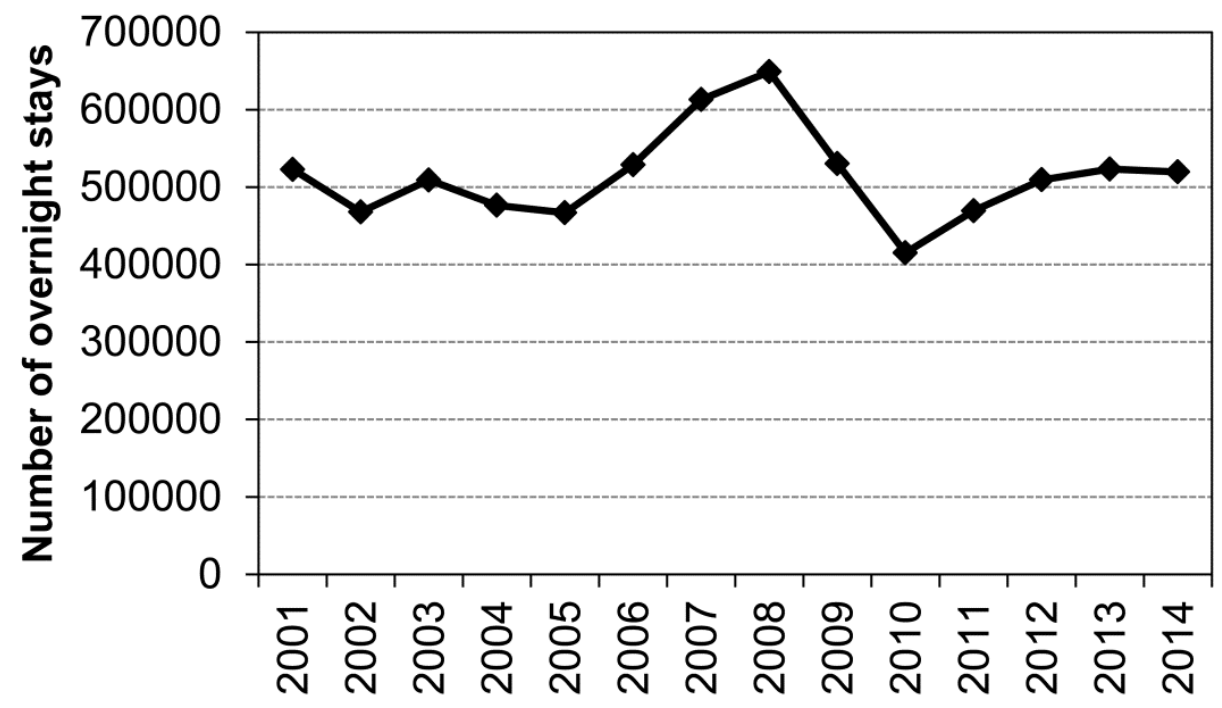

Figure 10

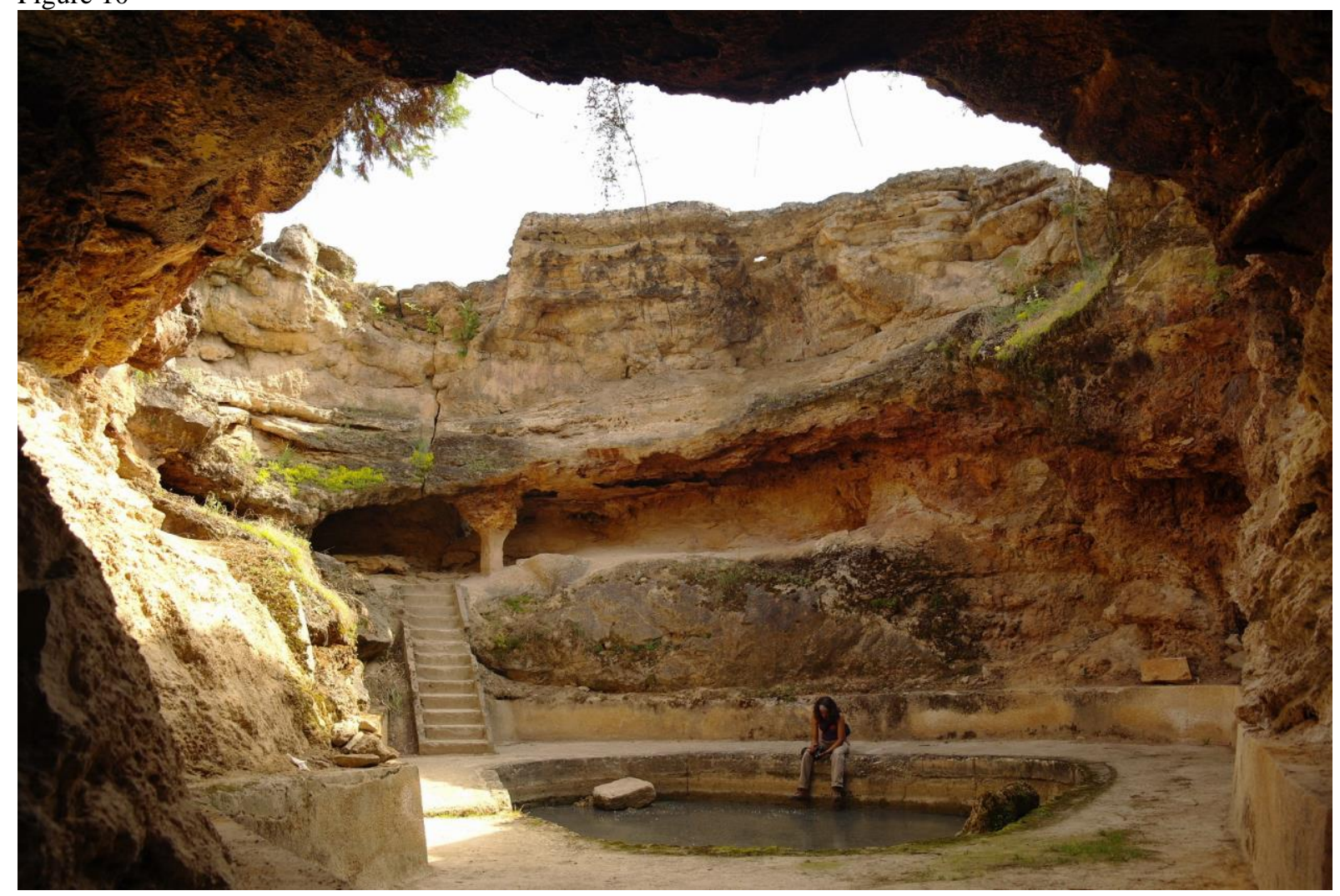


Figure 11

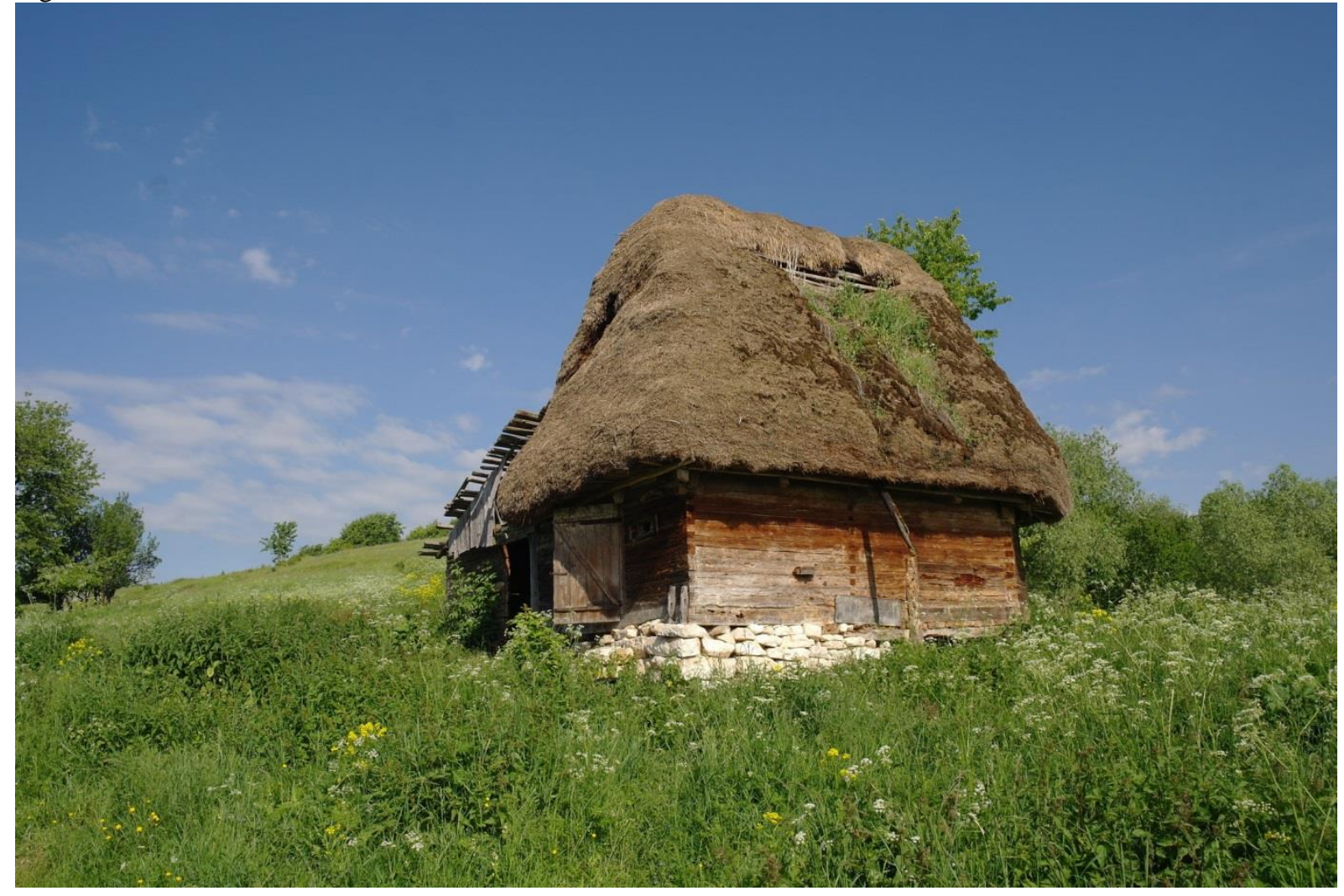

